\title{
Treatment of crude oil-contaminated water with chemically modified natural fiber
}

\author{
Jude Chinedu Onwuka ${ }^{1}$ Edith Bolanle Agbaji ${ }^{2}$. Victor Olatunji Ajibola ${ }^{2} \cdot$ Friday Godwin Okibe ${ }^{2}$
}

Received: 14 December 2017 / Accepted: 14 May 2018 / Published online: 24 May 2018

(c) The Author(s) 2018

\begin{abstract}
The dependence of Nigerian Government on foreign technology for oil spill cleanup in its water bodies does not add local content value in the development of the Nation's economy. Acetylation of natural cellulose gives a material with high sorption capacity for oil in water. This research investigates crude oil sorption from water using acetylated and unacetylated lignocellulose. Oil palm empty fruit bunch (OPEFB) and cocoa pod (CP) were acetylated under mild conditions. The acetylated (modified) and unacetylated (unmodified) sorbents were used to sorb oil from water, and their sorption capacities and mechanisms were compared. Paired $t$ test showed there was significant difference in the sorption capacities of modified and unmodified sorbents. Sorption of oil from water was found to be time and concentration dependent. Equilibrium studies showed that CP has higher sorption capacity than OPEFB and acetylation enhanced the crude sorption capacities of the sorbents. Crude oil sorption from water is a monolayer process that might have progressed from multilayer processes. Kinetic studies showed that sorption of crude oil by the sorbents was diffusion-controlled with the aid of physisorption and chemisorption mechanisms. Fourier transform infrared and scanning electron microscope analyses showed clear evidence of successful acetylation and oil sorption.
\end{abstract}

Keywords Oil palm empty fruit bunch (OPEFB) $\cdot$ Cocoa pod $\cdot$ Acetylation $\cdot$ Adsorption $\cdot$ Isotherm $\cdot$ Kinetics

\section{Introduction}

Niger delta region of Nigeria is the oil producing base of the country. Recently, oil spills in this region have escalated to serious dimensions due to pipeline vandalization and activities in the oil industry such as oil exploration, transportation, discharge from tankers. Most water bodies in this region are polluted with different hydrocarbon fractions. It was reported by Egwu (2012) that the oil industry spills incident rate has increased to about $80 \%$ between 1976 and 2008. In Nigeria, oil spills have led to loss of many lives, destruction of arable farmlands, fishing industry, recreational facilities, cultural areas and polluted water and air. The greatest concern is the long-term effects of both acute and chronic contaminations that can cause diseases (cancer in various

Jude Chinedu Onwuka

emperor20062003@yahoo.com

1 Department of Chemistry, Federal University Lafia, Lafia, Nasarawa, Nigeria

2 Department of Chemistry, Ahmadu Bello University Zaria, Zaria, Kaduna, Nigeria forms, rashes in children, etc.) for decades or more of such spills (Kaku Professional Engineers Limited, Nigeria 2012). At the moment, Nigerian oil industry is dependent on foreign experts, international oil companies and other foreign organizations to a large extent for spill management. This cannot add local content value in development and transfer of technology (Egwu 2012). Thus, there is an urgent need to develop a cost-effective method for cleaning up oil that will be based on cheap agro by-product raw materials found readily within the environment.

Natural fibers are lignocellulose which are made up of lignins, hemicellulose and cellulose having hydroxyl groups with varying reactivity. The surface of lignocellulosic materials is hydrophilic in nature due to the presence of hydroxyl groups. Chemical modification of lignocellulose is a good alternative to synthetic polymers which have strong affinity for organic compounds in water. Acetylation has received considerable attention more than any other chemical modification technique known (Rowell et al. 1994). Hydrophobic treatment of lignocellulosic materials like cotton (Adebajo and Frost 2004), rice straws (Sun et al. 2002), kenaf and jute (Rowell and Stout 1998; Rowell et al. 2002), rice husk 
(Thompson et al. 2010), corn cobs (Nwadiogbu et al. 2014), Delonix regia pods (Onwuka et al. 2016) by acetylation reaction has been reported to show very high capacity to sorb oil from spill sites. Agricultural waste sorbents such as empty fruit oil palm bunch (Elaeis guineensis) and cocoa pods are abundantly available in different parts of Nigeria, and no studies have been done yet on their modification under mild condition and their ability to sorb oil.

The oil palm empty fruit bunch (OPEFB) is part of the wastes generated from the preliminary steps for processing oil palm mill which involves removing the fruits from its bunches by a combined unit of sterilizer and rotary drum thresher (Kwasi 2002; Katamanee 2006). Oil palm cultivation cut across all the nine states of Niger Delta (Akwa Ibom, Abia, Rivers, Edo, Imo, Ondo, Bayelsa, Cross River and Delta) (PIND 2011). Palm oil mills produce a large amount of solid wastes. The remainder of the oil palm consists of huge amount of lignocellulosic materials such as oil palm fronds, trunks, palm kernel and empty fruit bunches. The residues contain 7.0 million tonnes of oil palm trunks, 26.2 million tonnes of oil palm fronds and 23\% of empty fruit bunch (EFB) per tonne of fresh fruit bunch (FFB) processed in oil palm mill. These residues may cause environmental pollution problems and spread diseases (Udoetok 2012).

Cocoa (Theobroma cacao) is produced in 14 states in Nigeria, and its exports have been and will continue to be a significant factor in the economic growth of Nigeria. Unfortunately, Nigeria cocoa output has declined from over 300,000 to 155,000 tonnes with average annual growth rates declining by $8.3 \%$ during $1992-1996$ periods (Daramola 2004). One of the factors responsible for this decline was the fact that most soils in southern Nigeria, where cocoa is mostly grown, and in parts of the humid tropics are acidic due to nature of their parent materials, high rainfall regime and intensity and associated leaching of nutrients and weathering (Adejobi et al. 2013).

This research is aimed at investigating how acetylation of natural cellulose will affect its ability and mechanism to remove crude oil from aqueous medium.

\section{Methodology}

\section{Sample collection and preparation}

Oil palm empty fruit bunch (OPEFB) and Cocoa pods (CP) were collected from a local farm at Achina town in Aguata local government of Anambra state, Nigeria. The samples were cut and ground in a mortar, and then thoroughly washed with distilled water to remove foreign materials and water-soluble components. The washed samples were initially air dried for $12 \mathrm{~h}$ and then oven-dried to a constant weight at $65{ }^{\circ} \mathrm{C}$ for $36 \mathrm{~h}$.
The material was then sieved with laboratory sieves to obtain homogenous particle sizes using the BS410/1986 laboratory test sieve. A mechanical sieve shaker was used to separate the sorbent into the desired particle size (i.e., $425-625 \mu \mathrm{m})$.

\section{Acetylation of the agro-waste}

Method described by Sun et al. (2004) and Onwuka et al. (2016) was adopted in acetylating these materials, although little modification was included. A portion $(2 \mathrm{~g})$ of sorbent was placed in a $250-\mathrm{mL}$ conical flask containing $60 \mathrm{~mL}$ of acetic anhydride and $0.6 \mathrm{~g}$ ( $1 \%$ of the solvent) $\mathrm{N}$-bromosuccinimide (NBS). The flask was placed in a temperature-controlled water bath set at $70{ }^{\circ} \mathrm{C}$ for $90 \mathrm{~min}$, under atmospheric pressure. Then, the conical flask was removed from the water bath and the hot reagent was decanted. The material was thoroughly washed with ethanol and acetone to remove unreacted acetic anhydride and acetic acid by-product. The products were allowed to dry in an oven set at $60^{\circ} \mathrm{C}$ for $16 \mathrm{~h}$ and later cooled in a desiccator and stored in a plastic container prior to analysis and crude oil sorption studies.

\section{Oil sorption capacity}

To simulate the situation of oil spill and minimize experimental variation, the crude oil sample was held in beakers for 1 day in open air to release volatile hydrocarbon contents. The raw and acetylated samples were subjected to crude oil sorption test.

To $100 \mathrm{~mL}$ of distilled water in a $250-\mathrm{mL}$ beaker, $2.5 \mathrm{~g}$ of crude oil was added. A portion $(0.5 \mathrm{~g})$ of the sorbent was added into the mixture in the beaker and left unperturbed for $10 \mathrm{~min}$. After $10 \mathrm{~min}$, the sorbent was removed using sieving net and left to drain by hanging the net over the beaker in an oven for $4 \mathrm{~h}$ at $60{ }^{\circ} \mathrm{C}$. The drained sample was weighed and recorded. This was repeated at different times $(5,10,15$, 20 and $25 \mathrm{~min}$ ) at constant concentration and also at different initial concentrations of crude oil $(1.25,2.5,3.75,5.0$ and $6.75 \mathrm{~g} / 100 \mathrm{~mL}$ of water) at constant time. The sorption capacity of the sorbent samples was calculated using the expression

Oil Sorption Capacity $=\frac{\text { New Weight Gained }}{\text { Original Weight }}$

and was recorded as gram per gram of sorbent. The procedure was carried out in triplicates and the mean of the results reported. 


\section{Statistical analysis}

Paired sample $t$ test in SPSS version 16 was used to compare the oil sorption capacities of the acetylated and unacetylated sorbents.

\section{Scanning electron microscope (SEM) analysis}

About $20 \mathrm{mg}$ of the oven-dried sample was sputter-coated with a gold layer in a sputter machine (quantum sputter) for a $90 \mathrm{~s}$. The SEM machine (Phenom World) was allowed to stabilize for $120 \mathrm{~s}$ before setting the parameters to be used. Imaging of the sample was done at $15 \mathrm{kV}$, pressure at $0.003 \mathrm{~Pa}$ and set at 1000 magnification.

\section{Fourier transform infrared (FTIR) analysis}

The FTIR spectra were recorded using Shimadzu-8400S Fourier Transform Infrared Spectrometer (FT-IR) over the spectral range of $4000-500 \mathrm{~cm}^{-1}$ with a resolution of $4 \mathrm{~cm}^{-1}$. This was carried out at the National Research Institute for Chemical Technology (NARICT) Zaria.

\section{Results and discussion}

\section{Scanning electron microscope (SEM) analysis}

Figure 1a, b shows notable variform sphericity particles of silica on the organic matrix of unmodified (unacetylated) and modified (acetylated) OPEFB (Kudaybergenov et al. 2012) which consist of cellulose, hemicellulose and lignin (Abdullah et al. 2011; Embrandiri et al. 2012). Figure 1a shows that unmodified OPEFB is solid with tiny pores which could be due to the coverage by plant surface wax. This according to Chung et al. (2011) could be attributed to the presence of crystallites in the unmodified sorbent. It was observed from Figs. $1 b$ and $2 b$ that the surface of the sorbents was roughened with different degree of wrinkles and grooves during the modification process. This increases the surface area of the modified sorbents. This could be as result of the removal of surface wax, namely lignin and hemicellulose from the sorbent, by the treatment with acetic anhydride (Johar et al. 2012). This was similarly reported by other researchers (Chung et al. 2011; Wang et al. 2012; Onwuka et al. 2016).

Figures $1 \mathrm{c}$ and $2 \mathrm{c}$ show that the pores which can store crude oil were covered completely in OPEFB and partially in CP. Thus, surface of crude oil-treated OPEFB was smoother than that of unmodified and modified OPEFB while macropores were seen in crude oil-treated CP. This is evident that crude oil was successfully sorbed on the surfaces of these sorbents.

\section{Fourier transform infrared (FTIR) spectra analysis}

The IR spectra of unmodified, modified and crude oil-treated OPEFB and CP are presented in Figs. 3 and 4, respectively.

FTIR spectra of the unmodified and modified sorbents showed evidence of acetylation with intense ester bands appearing and/or enhanced at $2931.90 \mathrm{~cm}^{-1}$ (C-H stretch in methyl and methylene groups), $1739.85-1753.35 \mathrm{~cm}^{-1}$ (carbonyl $\mathrm{C}=\mathrm{O}$ stretching of ester), $1375.29-1464.02 \mathrm{~cm}^{-1}$ $\left(\mathrm{C}-\mathrm{H}\right.$ in $\left.-\mathrm{O}(\mathrm{C}=\mathrm{O})-\mathrm{CH}_{3}\right), 1246.06-1255.70 \mathrm{~cm}^{-1}(\mathrm{C}=\mathrm{O}$ stretching of acetyl group) and $1020.38-1028.09 \mathrm{~cm}^{-1}$ (C-O stretching vibrations in cellulose) (Adebajo and Frost 2004; Azeh et al. 2013; Onwuka et al. 2016). The intense or enhanced hydrophobic bands in the modified spectra are as

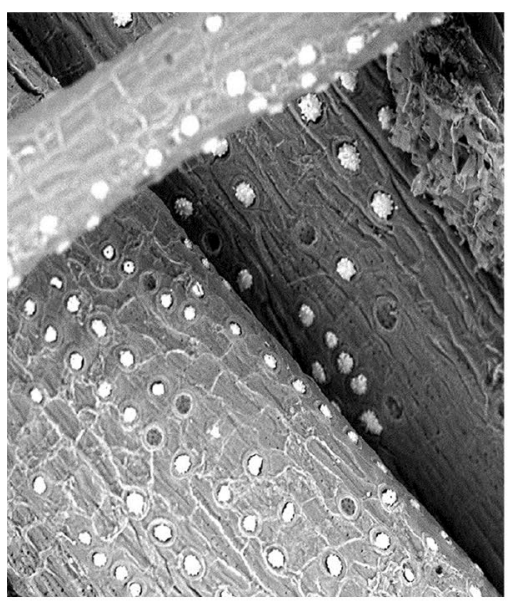

(a)

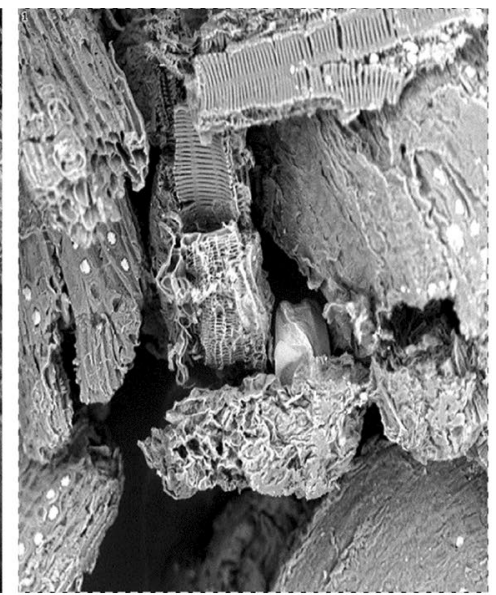

(b)

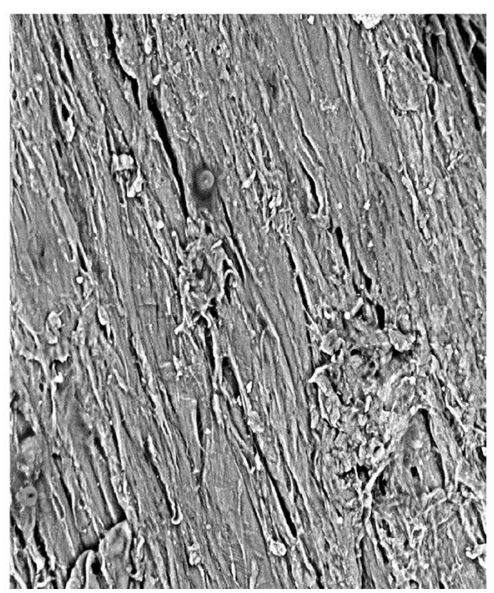

(c)

Fig. 1 SEM micrograph for unmodified (a), modified (b) and crude oil-treated (c) OPEFB 


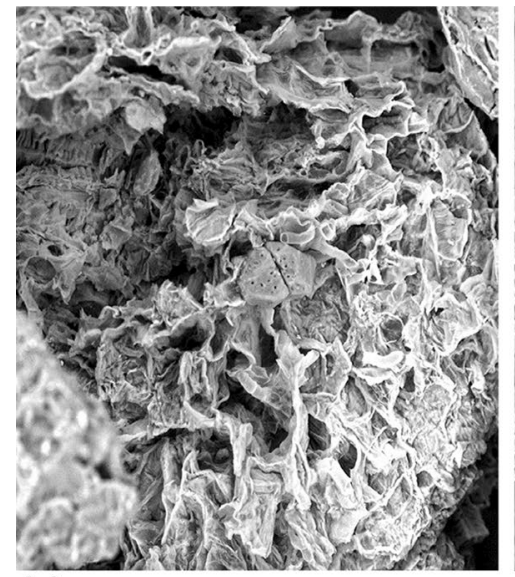

(a)

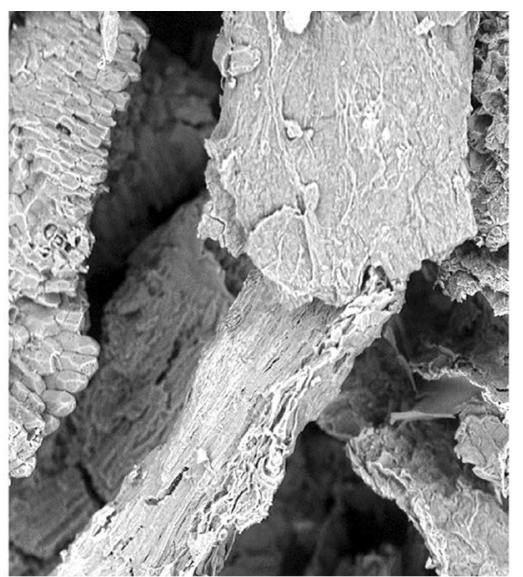

(b)

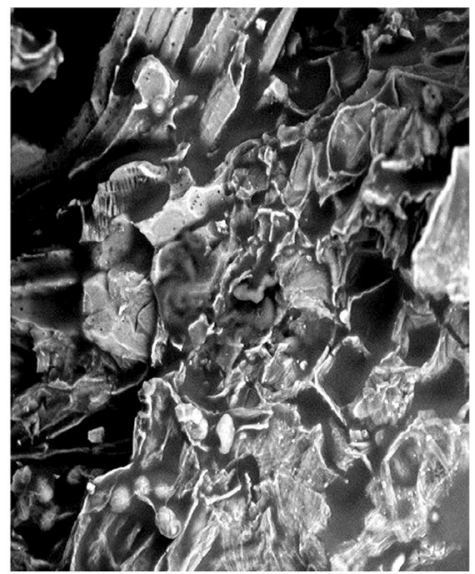

(c)

Fig. 2 SEM micrograph for unmodified (a), modified (b) and crude oil-treated (c) CP

Fig. 3 FTIR spectra for unmodified [green (1) spectra] and modified [red (2) spectra] and crude oil-treated [black (3) spectra] OPEFB

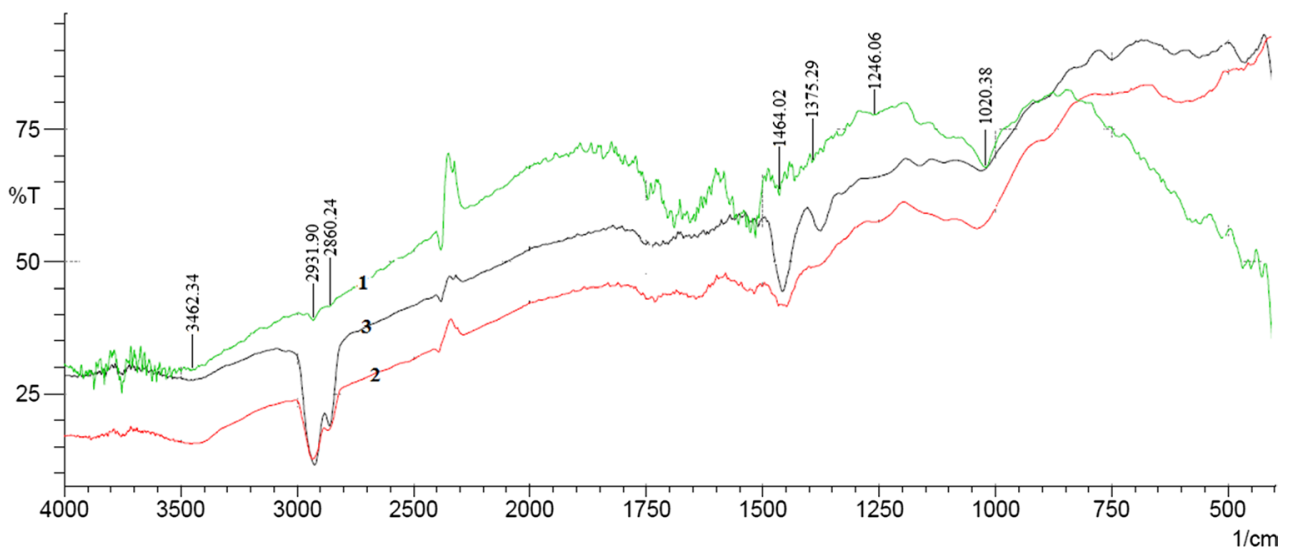

Fig. 4 FTIR spectra for unmodified [red (7) spectra] and modified [green (8) spectra] and crude oil-treated [black (9) spectra] CP

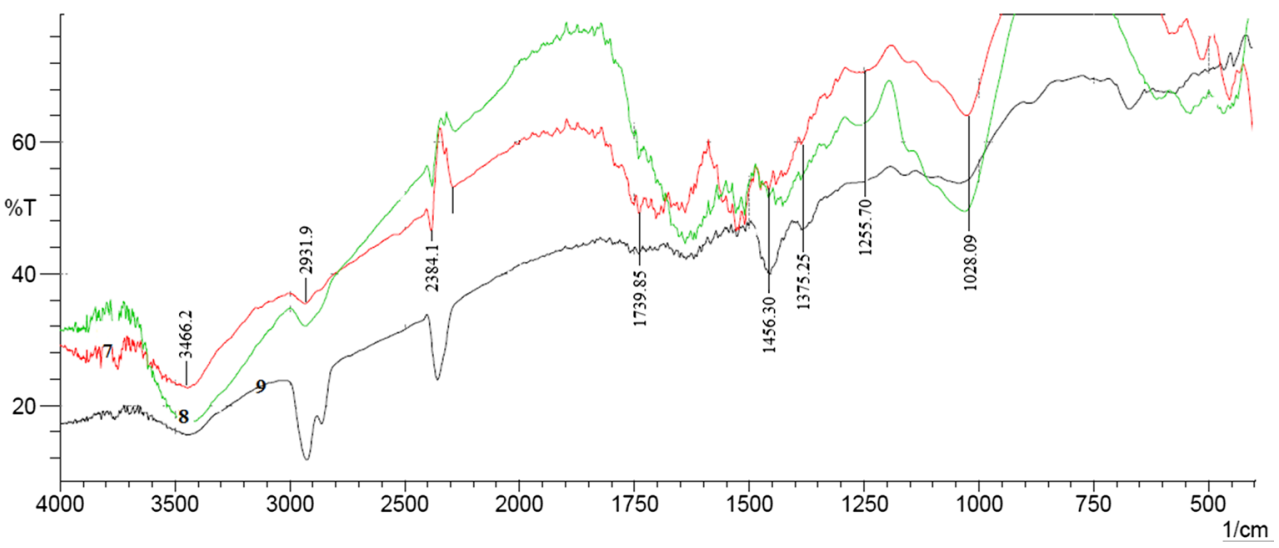

a result of substitution of hydroxyl groups at the surface of the lignocellulose, with acetyl groups.

Enhanced bands/peaks were clearly observed from the spectra of crude oil-treated sorbents, at about 2860.24-2931.90 $\mathrm{cm}^{-1}$ (C-H stretch in methyl and methylene groups), $2278.01-2384.10 \mathrm{~cm}^{-1}\left(\mathrm{CH}_{3}\right.$ group, stretching vibrations of aliphatic $\mathrm{CH}_{3}$ group) and $1375.29-1464.02 \mathrm{~cm}^{-1}\left(\mathrm{C}-\mathrm{H}\right.$ in $\left.-\mathrm{O}(\mathrm{C}=\mathrm{O})-\mathrm{CH}_{3}\right)$. These are hydrophobic functional groups, and hence, this confirms that crude oil was actually sorbed at the hydrophobic sites of the sorbents (Ibrahim et al. 2009; Kudaybergenov et al. 2012). 


\section{Oil sorption studies}

\section{Effect of initial crude oil concentration}

Figure 5 shows that oil sorption capacity of the modified sorbents was higher than that of the unmodified sorbents. It was observed that oil sorption capacity of modified OPEFB and unmodified CP increases with increase in the initial crude oil concentration up to $2.5 \mathrm{~g} / 100 \mathrm{~mL}$. Unmodified OPEFB and modified CP achieved equilibrium at 3.75 and $1.25 \mathrm{~g} / 100 \mathrm{~mL}$, respectively. After equilibrium was achieved, there was a decrease in oil sorption capacity with increase in the initial crude oil concentration.

The increase in oil sorption capacity can be attributed to adsorption of crude oil molecules at the hydrophobic reactive sites and also diffusion into the pores or hollow lumen of the sorbents (Wang et al. 2012). The decrease, on the other hand, could be attributed to increase pressure and desorption occurring at these reactive sites when the sites are already saturated by crude oil molecules (Thompson et al. 2010).

\section{Equilibrium studies of oil sorption}

Sorption capacities of the unmodified and modified samples were estimated by analyzing the isotherm data using common adsorption isotherm models. The correlation of equilibrium data using an equation is essential for practical sorption operations since the adsorption isotherms are important in describing how adsorbates will interact with adsorbents (Hashem et al. 2007). Coefficient of determination $\left(R^{2}\right)$ values within $0.43 \leq R^{2} \leq 0.83$ is moderate (Dowine and Heath 1974). The two isotherm equations adopted in this study to

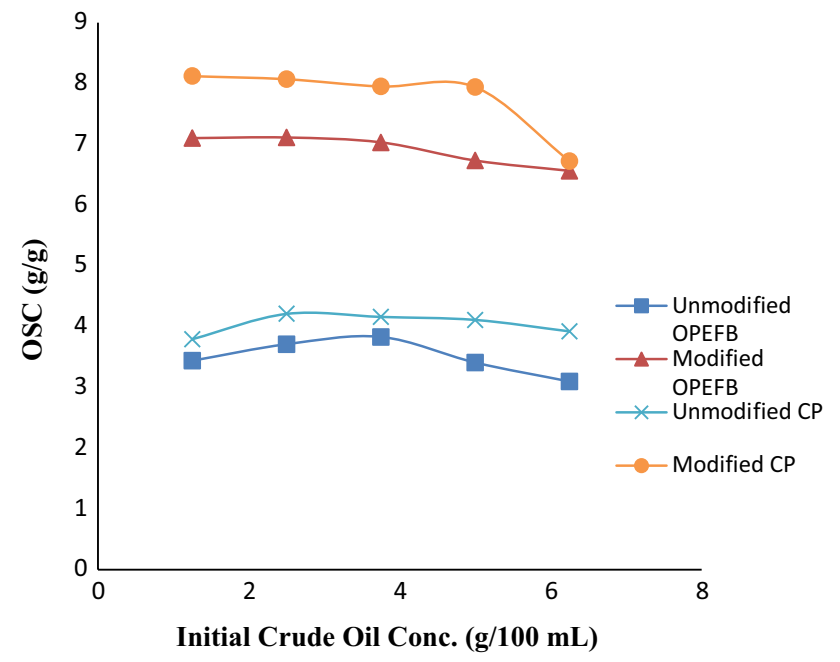

Fig. 5 Effect of initial crude oil concentration on oil sorption capacity (OSC) of the sorbents describe the sorption equilibrium are the linearized forms of Langmuir and Freundlich isotherm models.

\section{Langmuir isotherm}

Langmuir adsorption isotherm is applicable to monolayer sorption onto a surface having homogeneously distributed identical binding sites over the surface sorbent. The theory can also be adopted for a number of systems where the coverage is low, but it is more appropriate for the description of chemisorption. The Langmuir model was chosen for the estimation of maximum sorption capacity to biomass surface saturation.

The linearized form of Langmuir model is expressed as

$\frac{C_{\mathrm{e}}}{Q_{\mathrm{e}}}=\frac{1}{a b}+\frac{C_{\mathrm{e}}}{a}$

where $Q_{\mathrm{e}}$ is the mass of the solute sorbed per unit mass of sorbent $(\mathrm{g} / \mathrm{g}), a$ is the maximum oil sorption capacity (OSC) $(\mathrm{g} / \mathrm{g})$ to form a complete monolayer on the surface bound at high $C_{\mathrm{e}}(\mathrm{g} / 100 \mathrm{~mL})$, and $b$ is the Langmuir coefficient related to the affinity between the sorbent and sorbate $(100 \mathrm{~mL} / \mathrm{g}) . C_{\mathrm{e}}$ is the equilibrium adsorbate concentration in solution $(\mathrm{g} / 100 \mathrm{~mL})$. The plot of $C_{\mathrm{e}} / Q_{\mathrm{e}}$ against $C_{\mathrm{e}}$ gives a linear relationship which enables the values of $a$ and $b$ to be calculated from the intercept $\frac{1}{a b}$ and slope $\frac{1}{a}$ of the plot (Gupta and Rastogi 2007).

\section{Freundlich isotherm}

The Freundlich adsorption isotherm is a special case for heterogeneous surface and is usually used to model adsorption from solution. Thus, Freundlich model equation describes non-ideal sorption onto heterogeneous surfaces involving multilayer sorption. The adsorption isotherm is useful for predicting the capacity that an adsorbent has for adsorbing adsorbate (Weber 1973). The equation can be confidently used to explain nonlinear adsorption in a narrow range of adsorbate concentration. The steeper the isotherm, the more effective is the adsorbent. As the concentration increases, the effective capacity at the concentration level desired for adsorption increases (Weber 1973). The linearized Freundlich model equation can be expressed as

$\log Q_{\mathrm{e}}=\log K+(1 / n) \log C_{\mathrm{e}}$

where $Q_{\mathrm{e}}$ is the amount of adsorbate adsorbed per unit weight of sorbent, $K$ is Freundlich constant which is the relative indication of adsorption capacity $(100 \mathrm{~mL} / \mathrm{g}), C_{\mathrm{e}}$ is the equilibrium concentration of the adsorbent in solution, and $n$ is the constant, related to the intensity of adsorption on the adsorbent. A plot of $\log Q_{\mathrm{e}}$ against $\log C_{\mathrm{e}}$ gives a straight line with a slope $1 / n$ and an intercept of $\log K$. 
The summary of data obtained from equilibrium modeling of crude oil sorption is presented in Table 1. The Langmuir theoretical monolayer sorption capacity, $a$, for the optimum unmodified and modified OPEFB, and unmodified and modified $\mathrm{CP}$ is 3.04 and $6.48 \mathrm{~g} / \mathrm{g}$, and 3.97 and $6.65 \mathrm{~g} / \mathrm{g}$, respectively. This means that both unmodified $\mathrm{CP}$ and modified CP have higher crude oil sorption capacity than OPEFB. Based on the coefficient of determination $\left(R^{2}\right)$ values presented in Table 1, it can be deduced that the experimental data fitted the Langmuir model better than the Freundlich model as the $R^{2}$ values of the Langmuir model tend to be much closer to 1 than those obtained from the Freundlich isotherm. Hence, adsorption of crude oil from water by the sorbents is a chemisorption or monolayer sorption process. It was observed that the values of coefficient of determination for Freundlich isotherms of the modified sorbents are moderate. This suggests that crude oil sorption by modified sorbents could have progress from multilayer sorption process to homogeneous process. Thus, multilayer process contributed to monolayer sorption mechanism of crude oil sorption from aqueous solution by these modified sorbents.

The coefficient of determination values for Langmuir and Freundlich isotherms of modified sorbents was found to be higher than those of the unmodified. This suggests that acetylation enhances the process of crude oil sorption on to the surface of the sorbents by providing more hydrophobic reactive sites. Thus, there could be a relationship between extent of acetylation and crude oil sorption capacity of the modified sorbents. Thompson et al. (2010) reported similar findings for rice husks.

\section{Effect of contact time}

It can be observed from Fig. 6 that with the exception of modified OPEFB, all other sorbents (unmodified and modified) showed increase in oil sorption capacity with increase in contact time up to 15 min when the sorption process reached equilibrium. This may be due to adsorption of crude oil on the surface of the sorbents first, before the crude oil starts to penetrate the inner microscopic voids (Amer et al. 2007). Kudaybergenov et al. (2012) also reported that crude oil is first adsorbed by the macropores of the sorbents before it penetrates into the

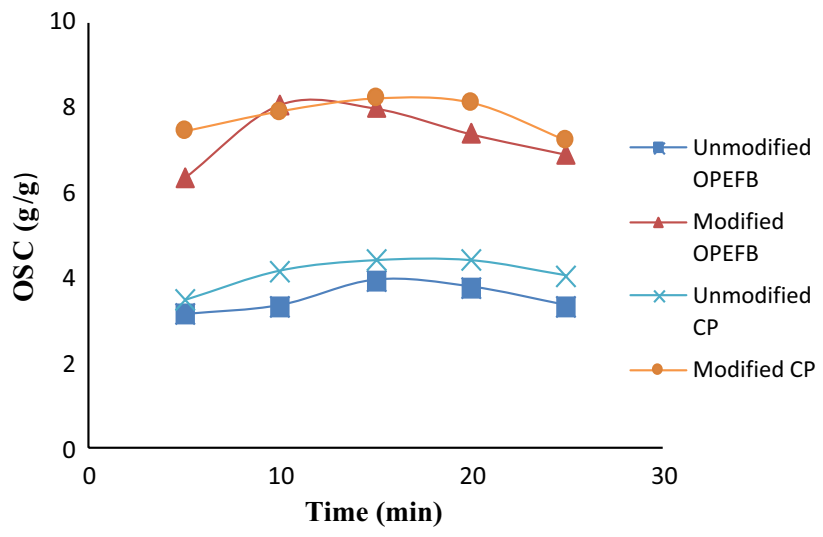

Fig. 6 Effect of contact time on crude oil sorption capacity (OSC) of the sorbents

micropores until equilibrium time is reached. The results also showed that the process was fast and stable because only a slight difference in oil sorption capacity was observed between the initial and final contact times (Thompson et al. 2010).

Similar findings were reported by Hussein et al. (2009), Thompson et al. (2010) and Kudaybergenov et al. (2012) on crude oil sorption by cotton fibers, rice husks (acetylated and unacetylated) and thermally treated rice husks, respectively.

\section{Kinetics of crude oil sorption}

To determine the mechanisms involved in the crude oil sorption from aqueous solution, the kinetic results obtained by calculating the oil sorption capacity (OSC) of sorbents at different contact time were analyzed using pseudo-first-order, pseudo-second-order, intra-particle diffusion and liquid film diffusion models. Coefficient of determination $\left(R^{2}\right)$ values within $0.43 \leq R^{2} \leq 0.83$ is considered moderate (Dowine and Heath 1974).

\section{Pseudo-first-order kinetics}

Pseudo-first-order equation for crude oil sorption is stated as:

$\ln \mathrm{OSC}_{t}=\ln \mathrm{OSC}_{0}-k_{1} t$

Table 1 The Langmuir and Freundlich isotherm data

\begin{tabular}{|c|c|c|c|c|c|c|c|c|}
\hline \multirow[t]{2}{*}{ Sample } & \multicolumn{4}{|l|}{ Langmuir model } & \multicolumn{4}{|l|}{ Freundlich model } \\
\hline & & $a(\mathrm{~g} / \mathrm{g})$ & $b(100 \mathrm{~mL} / \mathrm{g})$ & $R^{2}$ & & $K(100 \mathrm{~mL} / \mathrm{g})$ & $n$ & $R^{2}$ \\
\hline Unmodified OPEFB & $y=0.3296 x-0.136$ & 3.04 & -2.419 & $0.9811^{\mathrm{a}}$ & $y=-0.0571 x+0.5713$ & 3.73 & -17.5 & 0.1947 \\
\hline Modified OPEFB & $y=0.1544 x-0.029$ & 6.48 & -5.324 & $0.9976^{\mathrm{a}}$ & $y=-0.0386 x+0.8619$ & 7.28 & -25.9 & 0.4199 \\
\hline Unmodified CP & $y=0.252 x-0.019$ & 3.97 & -13.26 & $\mathbf{0 . 9 7 8 3}^{\mathrm{a}}$ & $y=0.0201 x+0.5936$ & 3.92 & 49.75 & 0.0093 \\
\hline Modified CP & $y=0.1504 x-0.066$ & 6.65 & -2.28 & $0.9961^{\mathrm{a}}$ & $y=-0.0832 x+0.9328$ & 8.57 & -12.02 & 0.4579 \\
\hline
\end{tabular}

a means the highest $R^{2}$ values

Moderate $R^{2}$ values are bolded 
where $\mathrm{OSC}_{0}$ is the minimum oil sorption capacity of the sorbent, $\mathrm{OSC}_{t}$ is the oil sorption capacity of the sorbent at time $t, t$ is the time in minutes, and $k_{1}$ is pseudo-first-order rate constant. The plot of $\mathrm{OSC}_{t}$ against $t$ gives a linear relationship representing Eq. 4, where $k_{1}$ is the slope and $\ln$ $\mathrm{OSC}_{0}$ is the intercept. When the coefficient of determination obtained in this plot is moderate, physisorption or surface reaction is regarded as either the controlling or the contributory mechanism in crude oil sorption at that particular time (Nwadiogbu et al. 2014; Onwuka et al. 2016).

\section{Pseudo-second-order kinetics}

Pseudo-second-order rate equation used is as follows:

$\left[\frac{1}{\mathrm{OSC}_{t}}\right]=k_{2} t+\left[\frac{1}{\mathrm{OSC}_{0}}\right]$

The plot of $\frac{1}{\mathrm{OSC}_{t}}$ against $t$ in Eq. 5 gives a linear relationship with $k_{2}$ as the slope, and $\frac{1}{\mathrm{OSC}_{0}}$ is the intercept. When the coefficient of determination obtained in this plot is moderate, it implies that chemisorption (chemical reaction) contributes or is the rate-controlling step for the mechanism at that particular time (Nwadiogbu et al. 2014; Onwuka et al. 2016).

\section{Intra-particle diffusion}

Intra-particle diffusion model is commonly used to determine the possibility of intra-particle diffusion being the ratedetermining mechanism (Srivastava et al. 2006). The model involves the transport of the adsorbate to the surface of the adsorbent particles and the diffusion of the solute molecules into the interior of the pores, which is usually a slow process. Equation representing this model is expressed as: (Igwe and Abia 2006; Subbaiah et al. 2008)

$\mathrm{OSC}_{t}=k_{3} \sqrt{t}+c$

where $k_{3}$ is the intra-particle diffusion rate constant, which can be evaluated from the slope of the linear plot of $\mathrm{OSC}_{t}$ versus $t^{1 / 2}$, and $c$ is the intercept. According to Eba et al. (2010), the intercept of the plot reflects the boundary layer effect. The larger the intercept, the greater the contribution of the surface sorption in the rate-controlling step. If the regression of OSC versus $t^{1 / 2}$ is linear and the plot passes through the origin, then intra-particle diffusion is the sole rate-limiting step. However, in the case where the plots do not pass through the origin, it suggests that the intra-particle diffusion is not the only mechanism involved in the sorption process due to some degree of boundary layer control (Bulut et al. 2008).

\section{Liquid film diffusion}

Boundary plays a major role in adsorption when sorbate molecules are transported from the liquid phase to the solid phase. The liquid film diffusion model may be applied as follows: (Bulut et al. 2008; Eba et al. 2010)

$-\ln (1-F)=k_{4} t$

where $k_{4}$ is the liquid film diffusion rate constant, $F$ is fractional attainment which is equal to $\mathrm{OSC}_{t} / \mathrm{OSC}_{\mathrm{e}}, \mathrm{OSC}_{t}$ is the oil sorption capacity of the sorbent at a particular time, $t$, and $\mathrm{OSC}_{\mathrm{e}}$ is oil sorption capacity of the sorbent at equilibrium. $\mathrm{OSC}_{\mathrm{e}}$ corresponds to the highest OSC obtained within the time range studied. A linear plot of $-\ln (1-F)$ against $t$ with zero intercept would suggest kinetics of the sorption process is controlled by diffusion through liquid film surrounding the solid sorbent. The small intercepts of liquid film diffusion plot will suggest that liquid film diffusion model might have some roles to play in the kinetics of acetylation (Eba et al. 2010). Data obtained from kinetic plots are summarized in Table 2.

Table 2 shows that the coefficients of determination values obtained from the different kinetic plots were generally poor except for unmodified CP. Thus, values of coefficient of determination cannot be used to predict the crude oil sorption mechanism of these sorbents using the proposed models. However, some useful observations can be made from the data.

Table 2 Kinetic data for crude oil sorption by the sorbents

\begin{tabular}{|c|c|c|c|c|c|c|c|c|c|c|c|}
\hline \multirow[t]{2}{*}{ Sample } & \multicolumn{3}{|c|}{ Pseudo-first order } & \multicolumn{3}{|c|}{ Pseudo-second order } & \multicolumn{3}{|c|}{ Intra-particle diffusion } & \multicolumn{2}{|c|}{ Liquid film diffusion } \\
\hline & $\mathrm{OSC}_{0}$ & $R^{2}$ & $k_{1}$ & $\mathrm{OSC}_{0}$ & $R^{2}$ & $k_{2}$ & $c$ & $R^{2}$ & $k_{3}$ & $R^{2}$ & $k_{4}$ \\
\hline Unmodified OPEFB & 3.23 & 0.1874 & -0.052 & 3.23 & 0.1818 & -0.0016 & 2.96 & 0.2321 & 0.1480 & 0.0683 & 0.0380 \\
\hline Modified OPEFB & 7.16 & 0.0118 & -0.0014 & 7.14 & $8 \mathrm{E}-30$ & $-6 \mathrm{E}-18$ & 6.86 & 0.0369 & 0.1280 & 0.0939 & 0.0646 \\
\hline Unmodified CP & 3.68 & 0.3414 & -0.007 & 3.64 & 0.3266 & -0.0018 & 3.23 & $0.4411^{\mathrm{a}}$ & 0.2308 & 0.0173 & -0.0232 \\
\hline Modified CP & 7.88 & 0.0132 & 0.0008 & 7.52 & 0.025 & -0.0002 & 7.75 & 0.0004 & 0.0078 & 0.0093 & 0.0206 \\
\hline
\end{tabular}

a means the highest $R^{2}$ values

Moderate $R^{2}$ values are bolded 
Table 3 Paired samples $t$ test for crude oil sorption capacity of modified and unmodified sorbents

\begin{tabular}{|c|c|c|c|c|c|c|c|c|c|}
\hline & & \multicolumn{8}{|c|}{ Paired differences } \\
\hline & & \multirow[t]{2}{*}{ Mean } & \multirow[t]{2}{*}{ SD } & \multirow[t]{2}{*}{ SE Mean } & \multicolumn{2}{|c|}{$95 \% \mathrm{CI}$ of the difference } & \multirow[t]{2}{*}{$t$} & \multirow[t]{2}{*}{$d f$} & \multirow[t]{2}{*}{ Sig. (2-tailed) } \\
\hline & & & & & Lower & Upper & & & \\
\hline \multicolumn{10}{|c|}{ Effect of contact time } \\
\hline OPEFB & Unmodified-modified & -3.82600 & 0.57869 & 0.25880 & -4.54454 & -3.10746 & -14.784 & 4 & $<0.0001$ \\
\hline $\mathrm{CP}$ & Unmodified-modified & -3.68000 & 0.30389 & 0.13590 & -4.05733 & -3.30267 & -27.078 & 4 & $<0.0001$ \\
\hline \multicolumn{10}{|c|}{ Effect of initial crude oil concentration } \\
\hline OPEFB & Unmodified-modified & -3.40800 & 0.17123 & 0.07658 & -3.62061 & -3.19539 & -44.504 & 4 & $<0.0001$ \\
\hline $\mathrm{CP}$ & Unmodified-modified & -3.72200 & 0.56015 & 0.25051 & -4.41752 & -3.02648 & -14.858 & 4 & $<0.0001$ \\
\hline
\end{tabular}

Table 2 shows that pseudo-first-order, pseudo-secondorder and liquid film diffusion rate constants are higher for the modified sorbents than the unmodified ones. This suggests that the rates of surface reaction, chemical reaction (chemisorption) and transport of solute from liquid to sorbent phase are faster in the modified sorbents than in the unmodified ones. This can be attributed to the high hydrophobic nature of the modified sorbents.

The intra-particle diffusion rate constants for modified sorbents were observed to be lower than those of unmodified sorbents. This implies that the diffusion of crude oil into the pores of modified sorbents was slower than its diffusion into the pores of unmodified sorbents. This may be due to reduction in the porosity of the sorbents after acetylation.

In the reaction kinetics (i.e., pseudo-first- and pseudosecond order) of the sorption process, the pseudo-first-order rate constants for all the sorbents were found to be lower than the pseudo-second-order rate constants. This means that surface reaction being the slowest step in the reaction kinetics is the rate-controlling step in the sorption process. This is supported by the fact that in crude oil sorption by unmodified CP, the coefficient of determination values (which was moderate) for pseudo-first-order one was higher than that of pseudo-second-order one, and this suggests that surface reaction is the rate-controlling mechanism in the sorption process while chemisorption was partly involved in the process. This suggests that rate constants are very sensitive to the determination of mechanism of oil sorption process, thus indicating the reliability of the rate constant technique in predicting oil sorption mechanism. Similar findings were reported by Onwuka et al. (2016) for crude oil sorption using acetylated and unacetylated Delonix regia pods (DRPs). However, these findings contradict reports by Asadpour et al. (2016), which states that rate of oil sorption onto the OPEFB fibers can be adequately described by the pseudo-second-order equation. The findings in this research remain logical because chemical reaction (chemisorption) cannot occur between the active sites on the surface of the sorbents and crude oil without surface reaction (physisorption) taking place first.

For crude oil sorption by unmodified CP, coefficient of determination values for some kinetic models was moderate. It was observed that intra-particle diffusion was the ratecontrolling mechanism for the sorption process, but it is not the sole mechanism since the line did not pass through the origin.

It was also observed that in all the sorption process by modified sorbents, there was greater contribution of surface sorption in the intra-particle diffusion because the intercepts of intra-particle diffusion model for modified samples are greater than those found for unmodified samples (Bulut et al. 2008). This is supported by the fact that pseudo-firstorder rate constants for sorption by modified sorbents are higher than those of unmodified ones which suggests that, for sorption process by modified sorbents, surface reactions are faster. Thus, acetylated materials are suitable sorbents for oil sorption.

\section{Statistical analysis of oil sorption data}

Paired $t$ test was used to compare the result of crude oil sorption capacities of unmodified and modified OPEFB and $\mathrm{CP}$ at different factors (i.e., contact time and initial crude oil concentration). Table 3 shows that there is significant difference between the oil sorption capacity of unmodified and modified sorbents at various contact times and initial crude oil concentrations. This is because all the $p$ values are less than $\alpha=0.05$ which implies that acetylation process actually enhanced the sorption capacity of these sorbents.

\section{Conclusion}

The sorbents were successfully modified and can also be used to remove crude oil from water. Acetylation enhances the crude oil sorption capacities of the sorbents, and the 
difference in the crude oil sorption capacities of the modified and unmodified sorbents is statistically significant.

Crude oil sorption from water using the modified and unmodified sorbents was found to be time and initial concentration dependent. Crude oil sorption capacity of $\mathrm{CP}$ is higher than that of OPEFB. Sorption of crude oil from water by these sorbents is a monolayer sorption process which started from multilayer processes. Kinetic investigations showed that crude oil sorption is diffusion-controlled with the aid of physisorption and chemisorption mechanism.

Acknowledgements We are grateful to the entire Staff of Chemistry Department, Ahmadu Bello University, Zaria, for their support during the course of this research work. Special thanks also go to Mr. Ochigbo and his team for their technical support. Mr. Mahmud Aboki of National Research Institute for Chemical Technology (NARICT) Zaria, Kaduna, Nigeria, is acknowledged for his assistance in FTIR analysis.

Author contributions JCO, EBA, and VOA designed the research; JCO and FGO carried out the laboratory work and did the kinetic modeling and statistical analyses while all the authors interpreted the results and participated in the writing of this research article.

\section{Compliance with ethical standards}

Conflict of interest The authors declare that they have no conflict of interest.

Availability of data and materials All data and materials relevant to this article have been included.

Consent for publication All authors have endorsed the publication of this research.

Open Access This article is distributed under the terms of the Creative Commons Attribution 4.0 International License (http://creativeco mmons.org/licenses/by/4.0/), which permits unrestricted use, distribution, and reproduction in any medium, provided you give appropriate credit to the original author(s) and the source, provide a link to the Creative Commons license, and indicate if changes were made.

\section{References}

Abdullah MA, Nazir MS, Wahjoedi BA (2011) Development of valueadded biomaterials from oil palm agro-wastes. In: 2nd International conference on biotechnology and food science, IPCBEE, vol 7. IACSIT Press, Singapore

Adebajo MO, Frost RL (2004) Acetylation of raw cotton for oil spill cleanup application: an FTIR and 13C MAS NMR spectroscopic investigation. Spectrochim Acta Part A Mol Biomol Spectrosc 60(10):2315-2321

Adejobi KB, Famaye AO, Akanbi OSO, Adeosun SA, Nduka AB, Adeniyi DO (2013) Potentials of cocoa pod husk ash as fertilizer and liming materials on nutrient uptake and growth performance of cocoa. Res J Agric Environ Manag 2(9):243-251

Amer AA, El-Maghrahy A, Malash GF, Nahla TA (2007) Extensive characterization of raw barley straw and study of the effect of steam pre-treatment. J Appl Sci Resour 3(1):1336-1342
Asadpour R, Sapari N, Isa MH, Kakooei S (2016) Acetylation of oil palm empty fruit bunch fiber as an adsorbent for removal of crude oil. Environ Sci Pollut Res 23(12):11740-11750

Azeh Y, Olatunji GA, Mohammed C, Mamza PA (2013) Acetylation of wood flour from four wood species grown in Nigeria Using vinegar and acetic anhydride. Int J Carbohydr Chem 20(2):85-96

Bulut E, Ozacar M, Sengil IA (2008) Adsorption of malachite green on to bentonite: equilibrium and kinetic studies and process design. Microporous Mesoporous Mater 115:234-246

Chung S, Suidan MT, Venosa AD (2011) Partially Acetylated Sugarcane Bagasse for Wicking Oil from Contaminated Wetlands. Chem Eng Technol 34(12):1989-1996

Daramola AG (2004) Competitiveness of Nigeria agriculture in a global economy. And dividends of democracy. Inaugural lecture series 36, FUTA, 2 March 2004

Dowine NM, Heath RW (1974) Basic Statistical methods, 4th edn. Harper and Row, New York

Eba F, Gueu S, Eya'A-Mvongbote A, Ondo JA, Yao BK, Ndong NJ, Kouya BR (2010) Evaluation of the absorption capacity of the natural clay from Bikougou (Gabon) to remove Mn(II) from aqueous solution. Int J Eng Sci Technol 2(10):5001-5016

Egwu SA (2012) Oil spill control and management. Pet Technol Dev J $1: 1-6$

Embrandiri A, Singh RP, Ibrahim HM, Ramli AA (2012) Land application of biomass residue generated from palm oil processing: its potential benefits and threats. Environmentalist 32(17):111-117

Foundation for Partnership Initiatives in the Niger Delta (PIND) (2011) A report on palm oil value chain analysis in the niger delta. Foundation for Partnership Initiatives in the Niger Delta (PIND), Abuja, Nigeria, $56 \mathrm{pp}$

Gupta VK, Rastogi A (2007) Biosorption of lead from aqueous solutions by green algae Spirogyra species. Kinetics and equilibrium studies. J Colloid Interface Sci 296:59-63

Hashem MA, Andelmonem RM, Farrage TE (2007) Human hair as sorbent to uptake dye stuff from aqueous solutions. Alex Eng J $1: 1-9$

Hussein M, Amer AA, El-Maghraby A, Taha NA (2009) Availability of barley straw: application on oil spill cleanup. Int J Environ Sci Technol 6(1):123-130

Ibrahim S, Ha-Ming A, Wang S (2009) Removal of emulsified food and mineral oils from wastewater using surfactant modified barley straw. Biores Technol 100:5744-5749

Igwe JC, Abia AA (2006) A bioseparation process for removing heavy metals from waste water using biosorbents. Afr J Biotechnol 5(12):1167-1179

Johar N, Ahmad I, Dufresne A (2012) Extraction, preparation and characterization of cellulose fibres and nanocrystals from rice husk. Ind Crops Prod 37:93-99

Kaku Professional Engineers Limited (Nigeria) (2012) Oil spill conference Nigeria, 106/110 Lewis Street (5th Floor), Lagos, Nigeria, 10-11 September 2012

Katamanee A (2006) Appropriate technology evaluation for oil palm product utilization in Krabi Province-Mahidol University. www. li.mahidol.ac.th/thesis/. Accessed 12 Apr 2015

Kudaybergenov KK, Ongarbayev EK, Mansurov ZA (2012) Thermally treated rice husks for petroleum adsorption. Int $\mathrm{J}$ Biol Chem $1: 3-12$

Kwasi P (2002) Origin of palm oil, small-scale palm oil processing in Africa. Agricultural services bulletin, vol 148. Food and agricultural organization (FAO), Rome

Nwadiogbu JO, Okoye PAC, Ajiwe VI, Nnaji NJN (2014) Hydrophobic treatment of corn cob by acetylation: kinetics and thermodynamics studies. J Environ Chem Eng 2:1699-1704

Onwuka JC, Agbaji EB, Ajibola VO, Okibe FG (2016) Kinetic studies of surface modification of lignocellulosic Delonix regia

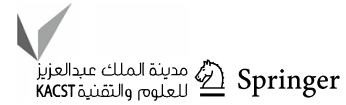


pods as sorbent for crude oil spill in water. $\mathrm{J}$ Appl Res Technol 14:415-424

Rowell RM, Stout HP (1998) Chapter 7: Jute and Kenaf. In: Lewin M, Pearce EM (eds) Handbook of fibre chemistry, 2nd edn. Marcel Dekker, Inc., New York, pp 65-504

Rowell RM, Simonson S, Hess S, Placket DV, Cronshaw D, Dunningham E (1994) Swelling of acetylated wood in organic solvent. Wood Fiber Sci 26:11-17

Rowell RM, Lange SC, Jacobson R (2002) Effects of moisture on aspen-fibre/polypropylene composites. In: Progress in wood fibres-plastic composite conference, Toronto, Canada

Srivastava VC, Swammy MM, Mall ID, Prasad B, Mishra IM (2006) Adsorptive removal of phenol by bagasse flies ash and activated carbon: equilibrium, kinetics and thermodynamics. Colloids Surf A Physicochem Eng Aspects 272:89-104

Subbaiah MV, Kalyani S, Reddy SGS, Boddu VM, Krishnaiah A (2008) Biosorption of $\mathrm{Cr}(\mathrm{VI})$ from aqueous solutions using Trametes vesicolor polyporous fungi. Eur J Chem 5(3):499-510

Sun XF, Sun R, Sun JX (2002) Acetylation of rice straw for oil sorption; with or without catalysts. J Agric Food Chem 50:6428
Sun XF, Sun RC, Sun JX (2004) Acetylation of sugarcane bagasse using NBS as a catalyst under mild reaction conditions for the production of oil sorption-active materials. Biores Technol 95(3):343-350

Thompson NE, Emmanuel GC, Adagadzu KJ, Yusuf NB (2010) Sorption studies of crude oil on acetylated rice husks. Scholars research library. Arch Appl Sci Res 2(5):142-151

Udoetok IA (2012) Characterization of ash made from oil palm empty fruit bunches (oefb). Int J Environ Sci 3(1):234-240

Wang JT, Zheng YA, Wang AQ (2012) Effect of kapok fibre treated with various solvents on oil absorbency. Ind Crops Prod 40:178-184

Weber WJ Jr (1973) The prediction of the performance of activated carbon for water treatment. A paper presented at a conference on, activated carbon in water treatment', organized by the Water Research Association held at the University of Reading, 3rd-5th April 1973, pp 53-71

Publisher's Note Springer Nature remains neutral with regard to jurisdictional claims in published maps and institutional affiliations. 